\title{
Impact of Cheese Rich in Conjugated Linoleic Acid on Low Density Lipoproteins Cholesterol: Dietary Intervention in Older People (CLADIS Study)
}

\author{
F. Limongi ${ }^{1, *, \#, \text { M. Noale }}{ }^{1, \#}$, A. Marseglia ${ }^{2}$, A. Gesmundo ${ }^{3}$, M. Mele ${ }^{4}$, S. Banni ${ }^{5}$, G. Crepaldi ${ }^{1}$, S. Maggi ${ }^{1}$ \\ ${ }^{1}$ National Research Council, Neuroscience Institute - Aging Branch, Via Giustiniani 2, 35128 Padova, Italy \\ ${ }^{2}$ Aging Research Center, Department Neurobiology, Care Sciences and Society, Karolinska Institutet, Stockholm, and Stockholm \\ University, Sweden \\ ${ }^{3}$ University of Padua, Department of Medicine - Geriatrics Section, Via Giustiniani 2, 35128 Padova, Italy \\ ${ }^{4}$ Dipartimento di Scienze Agrarie, Alimentari e Agro-ambientali, Università di Pisa, 56126, Pisa, Italy \\ ${ }^{5}$ Dipartimento Scienze Biomediche, Università di Cagliari, Cagliari Italy \\ ${ }^{\#}$ These authors contributed equally to the manuscript. \\ *Corresponding author: federica.limongi@libero.it
}

\begin{abstract}
Numerous studies demonstrated the possibility to improve the properties of dairy products by increasing Polyunsaturated Fatty and lowering the concentrations of saturated ones. The present study aimed to examine the impact of the consumption of a dairy product (Pecorino cheese) rich in Conjugated Linoleic Acid (CLA) on lipid and health parameters in elderly subjects. During the first phase of the study, a Pecorino cheese rich in CLA was produced from milk of ewes fed a specific diet. In the second phase, a double blind randomized crossover intervention study was conducted to verify the impact of enriched Pecorino cheese on LDL-Cholesterol (LDL-Ch) in elder individuals. 58 subjects were enrolled in a nursing home in Padua (Italy)a, with a mean age of $85.9 \pm 6.0$ years, 42 subjects $(72.4 \%)$ were women. Study participants were randomly assigned to two groups: in one, they had a daily intake of up to 90g of Pecorino cheese rich in CLA (higher than 2.5\%), in the other, they were given the same quantity of a Pecorino control cheese (CLA lower than $1 \%$ ) for a two-month period. The active phase was followed by a one-month wash out period. The crossover was then carried out and participants ate the other type of cheese for two months. No significant differences were found in relation to LDL-Ch (estimated mean difference between group: $3.07 \mathrm{mg} / \mathrm{dL}, \mathrm{p}=0.3171$ ), while participants who consumed enriched cheese had a lower increase in glycaemia with respect to those assuming the control cheese (estimated mean difference between group: $-0.07 \mathrm{~g} / \mathrm{L}, \mathrm{p}=0.0442$ ). A significant carry-over effect was detected for HDL-Ch, tryglicerides, creatinine, sodium and vitamin D. Participants who consumed Pecorino cheese rich in CLA did not register an increase in lipid levels. More studies on humans are necessary to evaluate the role of CLA enriched cheese on cardiovascular protection.
\end{abstract}

Keywords: dairy products, Pecorino cheese, Conjugated Linoleic Acid, lipid metabolism, old age

Cite This Article: F. Limongi, M. Noale, A. Marseglia, A. Gesmundo, M. Mele, S. Banni, G. Crepaldi, and S. Maggi, "Impact of Cheese Rich in Conjugated Linoleic Acid on Low Density Lipoproteins Cholesterol: Dietary Intervention in Older People (CLADIS Study)." Journal of Food and Nutrition Research, vol. 6, no. 1 (2018): 1-7. doi: $10.12691 /$ jfnr-6-1-1.

\section{Introduction}

Studies on the effects of dairy products consumption on health of elderly subjects and on its association with some cardiometabolic risk factors including inflammation, insulin resistance and lipid profile produced contradictory results. [1] It is nevertheless ever more apparent that positive or negative effects depend to a large extent on the characteristics of the single nutrients that dairy products contain. A primary role has been attributed to saturated fatty acids (SFA) of which dairy products are rich and that would act by increases in serum lipids and in particular Low Density Lipoproteins Cholesterol (LDL-Ch). [2,3,4]

Numerous studies have demonstrated that it is possible to improve the properties of dairy products by increasing polyunsaturated fatty acids (PUFA) and lowering the concentrations of saturated ones. [5]

In fact, fatty acids belonging to the $\mathrm{n}-3$ (such as alphaLinolenic acid, ALA), n-6, n-9 PUFA families and conjugated linoleic acid (CLA) seem to be able to modify lipid metabolism influencing gene expression and to regulate several disease states probably by interfering with the production of eicosanoid and endocannabinoid (EC). $[6,7]$ ALA, a major omega-3 fatty acid that appears to have several beneficial effects, can be modified by making changes in the diet of ruminants. [8] CLA and ALA may have synergic effects in modulating the EC system. [6]

The few studies on the effects of CLA, mostly conducted on animals, have highlighted many of its positive effects including protecting against cancer and 
atherosclerosis, stimulating some immune functions, reducing body fat and normalizing impaired glucose tolerance in type 2 diabetes. [9,10,11,12] A previous clinical study based on consumption of Pecorino cheese enriched with CLA and ALA (more than $2 \%$ and $1.5 \%$ of total lipids, respectively) showed a positive effect in the control of blood cholesterol and anandamide production. [6] From a recent review and meta-analysis on the association of foods enriched in CLA and CLA supplements with lipid profile in human it emerged that no studies on subjects aged 65 years or more were carried out [12].

The aim of the current study was to evaluate the impact of consumption of Pecorino rich in CLA and ALA, hereafter referred to as "enriched Pecorino cheese", on lipid profile, kidney function, inflammatory markers, glycaemia and vitamin D levels of elderly residents in a nursing home.

\section{Materials and Methods}

CLADIS was an intervention study, which was carried out over a 30-month period and that included two different phases: in the first one, the production of enriched Pecorino cheese was conducted; in the second one, a double blind randomized crossover trial was conducted in elderly residents of a nursing home to study the effect of consumption of enriched Pecorino cheese.

\subsection{First Phase: Production of Enriched Pecorino Cheese}

The goal of this phase was to produce enriched Pecorino cheese containing similar or higher concentrations of CLA and ALA to the cheese adopted in a previous clinical study. [6] In that study, in fact, a Pecorino cheese enriched with CLA and ALA (more than $2 \%$ and $1.5 \%$ of total lipids, respectively) showed a positive effect in the control of blood cholesterol and anandamide production. At this aim, a feeding protocol based on linseed supplementation was applied in a commercial dairy sheep farm in order to produce milk with the specific fatty acid composition needed to obtain the enriched Pecorino cheese. The effectiveness of linseed supplementation as feeding strategy to obtain enriched milk was previously published by Mele et al. $[13,14]$

At the same time, a survey was carried out in order to select Pecorino cheese low in CLA and ALA. At this aim, samples of Pecorino cheese from twelve winter production batches from four dairy plants in Tuscany and Sardinia were collected. Winter batches were chosen on the basis of the well-known seasonal variation of CLA and LNA content in sheep milk. Milk produced in the winter season, in fact, contains lower percentages of CLA and Linoleic Acid (LNA) than milk produced during the grazing season. The objective of the survey was to select a controlPecorino cheese low in CLA and ALA containing less than $1.5 \%$ and less than $1.2 \%$ of total fat for CLA and ALA, respectively.

\subsubsection{Chemical Analysis of Pecorino Cheese}

Samples from three different production batches were collected from both control and enriched Pecorino cheese in order to assess the nutritional characteristics of the cheese and the exact amount of CLA and ALA provided to the subjects enrolled for the study.

At this aim, cheese samples were analysed for fat content according to Gerber-Van Gulik (ISO, 1975) [15]. Dry matter, crude protein and ash contents were determined according to AOAC (1990) [14]. Moreover fatty acid composition and cholesterol content was analysed according to Mele et al. [14]

\subsection{Second Phase: the Double Blind Randomized Crossover Trial}

The primary objective of the second phase of the CLADIS study was to verify the impact of enriched Pecorino cheese on LDL-Ch in elder individuals. The study's secondary aims were related to the investigation of the impact of enriched Pecorino cheese on HDL-Ch, Triglycerides, Glycaemia and inflammatory markers.

This study was conducted according to the guidelines laid down in the Declaration of Helsinki and all procedures involving human subjects were approved by the local Ethics Committee ("Comitato Etico per la Sperimentazione della Provincia di Padova", n.prot. 18/2011/967). All the participants were informed about the objectives and modality of the study and written informed consent was obtained from all subjects.

\subsubsection{Study Population}

Fifty-eight residents of the OIC Foundation nursing home located in Padua (Italy) were screened and randomised. Study inclusion criteria were age range $\geq 60$ years, availability to participate and a declaration that they liked cheese. Exclusion criteria included severe diseases (end stage), physical and/or mental disability, current treatment with statins, other hypolipidemic drugs, corticosteroids, allergy or intolerance to dairy products, insulin-dependent diabetes. Subjects satisfying the inclusion criteria were randomised into two treatment groups: thirty-six subjects were assigned to group A and 22 to group B. This arrangement was decided upon because of logistical considerations, each of the groups were housed in different buildings of the same nursing home. For 2 months the subjects of Group A received a daily intake of up to $90 \mathrm{~g}$ of enriched Pecorino cheese, while those in Group B received a daily intake of up to 90 $\mathrm{g}$ of control Pecorino cheese. The Pecorino cheese was incorporated into the nursing home food menu, both natural and cooked, served also together with toasted bread or vegetables. The daily Pecorino cheese portion supplemented the usual nursing home diet. Health workers in the nursing home were asked to check the daily assumption of the Pecorino cheese portion.

After the first period of cheese consumption, there was a 1 month washout period which was followed by a crossover when the diets were switched. Participants, care providers and those assessing the outcomes were blinded to Pecorino cheese type assignment.

After the initial screening (V0), the subjects were exhaustively assessed at the study baseline examination (V1) and at follow-up examinations which took place two months later when the first period of cheese consumption 
was completed (V2); one month later at the end of the washout period (three months after baseline) (V3); two months later at the end of the second period of cheese consumption (five months after baseline) (V4) (Figure 1).

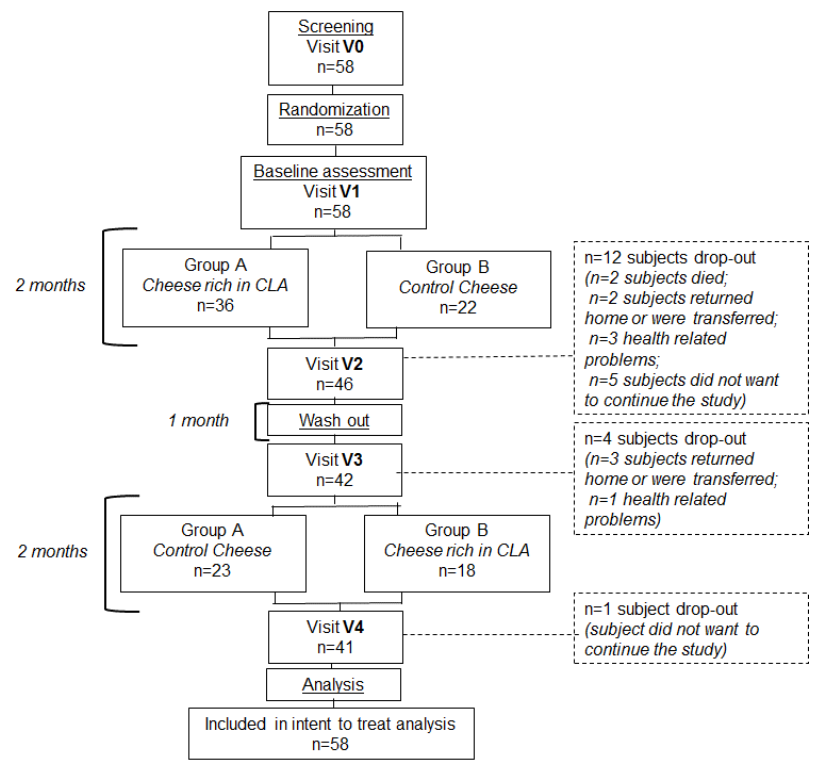

Figure 1. CLADIS cross-over study design

\subsubsection{Assessment}

The subjects meeting the study's eligibility requirements were identified through the screening phase. Those eligible who agreed to participate in the study underwent a baseline examination (V1) including a physical examination, a pharmacological, physiological and pathological history evaluation. Fasting blood samples were collected from all of the participants. At baseline and at the subsequent examination (V2, V3, and V4 months after baseline), the following parameters were determined: lipid profile (High Density Lipoprotein-Cholesterol, HDL$\mathrm{Ch}$; Low Density Lipoprotein-Cholesterol, LDL-Ch; Total Cholesterol, Triglycerides); kidney function and serum electrolytes parameters (creatinine, calcium, sodium, potassium); inflammatory markers (C-reactive Protein (CRP)); glycaemia and Vitamin D 25hydroxycholecalciferol (Vit D). All blood tests was performed at the Laboratories of the Abano Terme General Hospital (Padua). Height and weight were measured with the subject barefooted and lightly dressed. Body weight was measured on a balance beam platform scale to the nearest $0.1 \mathrm{~kg}$. Height was taken by a stadiometer at head level to the nearest centimeter with the subject standing barefoot, with feet together. Body Mass Index (BMI) was calculated as weight divided by height squared $\left(\mathrm{kg} / \mathrm{m}^{2}\right)$.

\subsubsection{Sample size}

The primary objective of the second phase of the CLADIS study was to verify the impact of enriched Pecorino cheese on LDL-Ch in elder individuals. The sample size was determined on the basis of a pilot study which found a difference of $8.82 \mathrm{mg} / \mathrm{dl}$ in LDL-Ch values in individuals assuming CLA-enriched dairy foods, with a standard deviation of individual differences of 19.35 . Considering a $20 \%$ drop-out, a power of 0.90 , an alpha of
0.05 , and assuming that no carry-over effects were present, an overall sample size of 68 was calculated using the following formula (1):

$$
\mathrm{n}=\frac{\sigma_{d}^{2}\left(z_{1-a / 2}+z_{1-\beta}\right)^{2}}{2 \Delta^{2}}
$$

\subsubsection{Statistical Analyses}

The data are shown as means and standard deviations (SD) for quantitative measures, and frequency and percentages for all discrete variables. The baseline characteristics of the subjects in Group A (eating in the first period enriched Pecorino cheese) and Group B (eating in the first period control Pecorino cheese) were compared using independent sample t-tests or Wilcoxon rank-sum tests for quantitative variables, and Chi-squared or Exact test was used for categorical variables.

The primary outcome analyses focused on LDL-Ch change, and repeated measures ANOVA was carried-out using the SAS Mixed procedure. The following factors were included: treatment (A-enriched Pecorino cheese; Bcontrol Pecorino Cheese), period, sequence (AB; BA), within-patient-sequence. The presence of carry-over treatment effects was tested with a significance level of 0.10 . In case of presence of carry-over or period effect, comparisons were based exclusively on the data collected at the end of the first period. Tukey adjustment for multiple comparisons were considered. The variations in other laboratory parameters (HDL-Ch, Total Cholesterol, Glycaemia, Calcium, Sodium, Creatinine, Triglycerides, Vit D, CRP) were evaluated following the same procedure.

Intention-to-treat (ITT) analyses were considered using multiple imputation (Markov chain Monte Carlo multiple imputation) of missing outcomes, through Proc MI; 30 imputed datasets were then combined considering Proc MI Analyze.

All tests were conducted at an alpha-level $=0.05$.

Statistical analyses were carried out using SAS System for Windows 9.4 (SAS Institute, Cary, NC).

\section{Results}

\subsection{First phase}

\subsubsection{Cheese characteristics}

The energy value of cheese was obtained using the following conversion factors: $9 \mathrm{kcal} / \mathrm{g}$ and $4 \mathrm{kcal} / \mathrm{g}$, for fat and protein content, respectively (EU regulation 1169/2011). The application of the feeding protocol to the dairy flock allowed to obtain enriched milk with a very high content of polyunsaturated fatty acids omega-3 (PUFA n-3) and CLA, if compared to the fatty acid composition of control cheese. The content of PUFA n-3, in fact, increased by nearly $145 \%$, whereas the content of CLA increased by more than $90 \%$. Similar results were previously obtained by applying the same feeding strategy. More than $80 \%$ of the total PUFA n-3 was ALA that accounted for nearly $2.2 \%$ of total fat. As regard CLA, the main isomers was CLA c9, t11 that accounted for more than $90 \%$ of total CLA isomers. These results were very 
closed to that reported by Mele et al. [14] by applying the same feeding protocol to dairy ewes.

The chemical and nutritional characteristics of both control and enriched cheese were reported in the Table 1.

Table 1. First Phase of the CLADIS Study: Chemical and Nutritional Characteristics of Control and Enriched Pecorino Cheese Applied in the Trial

\begin{tabular}{llcccc}
\hline & & \multicolumn{2}{c}{ Control cheese } & \multicolumn{2}{c}{ Enriched cheese } \\
\cline { 3 - 6 } & & Mean & SD & Mean & SD \\
\hline Energy & Kcal/100 g cheese & 355.9 & 4.2 & 353.6 & 3.8 \\
Moisture & $\mathrm{g} / 100 \mathrm{~g}$ cheese & 38.4 & 1.2 & 38.7 & 1.2 \\
Crude fat & $\mathrm{g} / 100 \mathrm{~g}$ cheese & 28.5 & 1.1 & 28.4 & 1.3 \\
Crude protein & $\mathrm{g} / 100 \mathrm{~g}$ cheese & 24.8 & 0.9 & 24.4 & 0.8 \\
Ashes & $\mathrm{g} / 100 \mathrm{~g}$ cheese & 8.1 & 0.2 & 7.9 & 0.1 \\
SFA & $\mathrm{g} / 100 \mathrm{~g}$ fatty acids & 68.0 & 2.1 & 62.0 & 1.8 \\
Unsaturated & $\mathrm{g} / 100 \mathrm{~g}$ fatty acids & 32.0 & 1.5 & 38.0 & 1.4 \\
fatty acids & & & & \\
PUFA omega-6 & $\mathrm{g} / 100 \mathrm{~g}$ fatty acids & 2.0 & 0.1 & 1.9 & 0.1 \\
PUFA omega-3 & $\mathrm{g} / 100 \mathrm{~g}$ fatty acids & 1.1 & 0.0 & 2.7 & 0.0 \\
CLA & $\mathrm{g} / 100 \mathrm{~g}$ fatty acids & 1.3 & 0.0 & 2.5 & 0.0 \\
Cholesterol & $\mathrm{mg} / 100 \mathrm{~g}$ cheese & 63.7 & 1.5 & 58.6 & 1.4 \\
\hline
\end{tabular}

SD, Standard Deviation

\subsection{Second Phase}

58 subjects were enrolled in a nursing home in Padua (Italy), in January 2012; no further subjects satisfied the inclusion criteria. Thirty-six subjects were assigned to group A (Cheese Rich in CLA) and 22 to group B (Control Cheese). 46 participated at visit V2, and 42 at visit V3. The field study was concluded in August 2012: 41 subjects completed the study, 23 in the Control Cheese group and 18 in Cheese rich in CLA group.

Participants' characteristics at study baseline (V1) with regard to sex, age, education, smoking and drinking (wine or beer) habits and self-rated health, all outlined in Table 2, were comparable. Mean laboratory values of the two treatments groups at baseline, outlined in Table 3, were not significantly different.

Table 4 outlines the variations in laboratory parameters with respect to baseline values. Analysis of variations of the primary outcome LDL-Ch after enriched or control Pecorino cheeses consumption, with respect to baseline values, did not uncover statistically significant differences $(p=0.3171)$. The difference across groups was not significant with regard to total cholesterol, CRP and calcium, while for glycaemia the difference was statistically significant: the participants who consumed enriched Pecorino Cheese had a lower mean increase in Glycaemia with respect to those assuming the Control Pecorino Cheese $(p=0.0442)$. A significant carry-over effect was detected for HDL-Ch and Vit D. Considering only the first period, the difference across groups was statistically significant for HDL-Ch $(p=0.0111$; the participants who ate enriched Pecorino Cheese had a lower mean decrease in HDL-Ch with respect to their counterparts) and for Vit D $(\mathrm{p}<0.0001$; the participants who ate enriched Pecorino cheese had a lower mean decrease in Vit D with respect to their counterparts). As far as Triglycerides, Creatinine and Sodium were concerned, a significant period effect was detected; no significant differences across Groups were found considering only data from the first period.
Table 2. Second Phase of the CLADIS Study: Baseline Characteristics of Subjects (Data are Means and Standard Deviation - SD, Unless Otherwise Specified)

\begin{tabular}{|c|c|c|c|c|c|}
\hline & \multicolumn{2}{|l|}{$\begin{array}{l}\text { Group A } \\
\text { Enriched } \\
\rightarrow \text { Control } \\
\text { Cheese } \\
(n=36)\end{array}$} & \multicolumn{2}{|c|}{$\begin{array}{l}\text { Group B } \\
\text { Control } \\
\rightarrow \text { Enriched } \\
\text { Cheese } \\
(\mathrm{n}=22)\end{array}$} & \multirow[t]{2}{*}{$\mathrm{p}$-value } \\
\hline & Mean & $\mathrm{SD}$ & Mean & SD & \\
\hline \multicolumn{6}{|l|}{ Demographic } \\
\hline Gender (females), n (\%) & $24(66.7)$ & & $18(81.8)$ & & 0.210 \\
\hline Age (years) & 86.7 & 5.3 & 84.5 & 6.9 & 0.144 \\
\hline Education, $\mathrm{n}(\%)$ & & & & & 0.241 \\
\hline $\begin{array}{l}\text { Degree or } \\
\text { University Degree }\end{array}$ & $1(2.8)$ & & $0(0.0)$ & & \\
\hline $\begin{array}{l}\text { Graduated High } \\
\text { School }\end{array}$ & $8(22.2)$ & & $5(22.7)$ & & \\
\hline Middle School & $4(11.1)$ & & $0(0.0)$ & & \\
\hline Primary School & $22(61.1)$ & & $13(59.1)$ & & \\
\hline None & $1(2.8)$ & & $4(18.2)$ & & \\
\hline \multicolumn{6}{|l|}{$\begin{array}{l}\text { Anthropometric } \\
\text { Characteristics } \\
\text { and Lifestyle }\end{array}$} \\
\hline Height (cm) & 154.2 & 7.5 & 150.4 & 8.3 & 0.078 \\
\hline Weight (kg) & 64.9 & 14.0 & 61.0 & 10.9 & 0.1495 \\
\hline BMI $(\mathrm{kg} / \mathrm{m} 2)$ & 27.3 & 6.0 & 27.0 & 4.7 & 0.826 \\
\hline Abdominal circumf. $(\mathrm{cm})$ & 94.2 & 14.6 & 95.1 & 11.8 & 0.813 \\
\hline Hip circumference $(\mathrm{cm})$ & 105.8 & 11.9 & 105.1 & 9.3 & 0.881 \\
\hline $\begin{array}{l}\text { Smoking status, n (\%) } \\
\text { Non smoker }\end{array}$ & $20(55.6)$ & & $14(66.7)$ & & 0.072 \\
\hline Yes, present smoker & $0(0.0)$ & & $2(9.5)$ & & \\
\hline Yes, former smoker & $16(44.4)$ & & $5(23.8)$ & & \\
\hline \multicolumn{6}{|l|}{ Wine/beer drinker, n (\%) } \\
\hline No & $18(50.0)$ & & $11(52.4)$ & & 0.248 \\
\hline Yes, present & $13(36.1)$ & & $4(19.1)$ & & \\
\hline Yes, former & $5(13.9)$ & & $6(28.6)$ & & \\
\hline
\end{tabular}

SD, Standard Deviation

Table 3. Second Phase of the CLADIS Study: Baseline Laboratory Examinations

\begin{tabular}{|c|c|c|c|c|c|}
\hline & \multicolumn{2}{|c|}{$\begin{array}{l}\text { Group A } \\
\text { Enriched } \\
\rightarrow \text { Control } \\
\text { Cheese } \\
(\mathrm{n}=36)\end{array}$} & \multicolumn{2}{|c|}{$\begin{array}{l}\text { Group B } \\
\text { Control } \\
\rightarrow \text { Enriched } \\
\text { Cheese } \\
(n=22)\end{array}$} & \multirow[t]{2}{*}{ p-value } \\
\hline & Mean & SD & Mean & SD & \\
\hline \multicolumn{6}{|l|}{ Lipid profile } \\
\hline LDL-Ch, mg/dL & 135.0 & 29.0 & 139.8 & 35.3 & 0.574 \\
\hline HDL-Ch, mg/dL & 59.9 & 15.3 & 62.4 & 18.3 & 0.581 \\
\hline Total Cholesterol, mg/dL & 216.6 & 33.7 & 223.8 & 40.6 & 0.464 \\
\hline Tryglicerides, mg/dL & 106.8 & 48.7 & 106.2 & 51.4 & 0.968 \\
\hline
\end{tabular}

Kidney function

and serum electrolytes

parameters

Creatinine, $\mathrm{mg} / \mathrm{dL}$

Calcium, mg/dL

Sodium, $\mathrm{mmol} / \mathrm{L}$

$\begin{array}{ccccc}1.0 & 0.3 & 1.1 & 0.4 & 0.142 \\ 9.8 & 0.3 & 10.1 & 0.7 & 0.181 \\ 139.8 & 3.3 & 140.9 & 2.7 & 0.213\end{array}$

Inflammatory markers

CRP, g/L

Glycaemia, g/L

$\begin{array}{lllll}0.9 & 0.2 & 0.8 & 0.1 & 0.172\end{array}$

Vit D, nmol/L

$\begin{array}{lllll}86.5 & 35.1 & 95.4 & 44.9 & 0.259\end{array}$


Table 4. Second Phase of the CLADIS Study: Mean Difference in Laboratory Examinations (After Intervention - Before Intervention), Within Group and Between Group

\begin{tabular}{|c|c|c|c|c|c|c|c|}
\hline & \multicolumn{4}{|c|}{$\begin{array}{l}\text { Mean Difference } \\
\text { Within Group } \\
\text { After intervention }\end{array}$} & \multicolumn{3}{|c|}{$\begin{array}{l}\text { Mean Difference } \\
\text { Between Group } \\
\text { After intervention }\end{array}$} \\
\hline & \multicolumn{2}{|c|}{$\begin{array}{l}\text { Enriched } \\
\text { Cheese } \\
(\mathrm{n}=58)\end{array}$} & \multicolumn{2}{|c|}{$\begin{array}{l}\text { Control } \\
\text { Cheese } \\
(\mathrm{n}=58)\end{array}$} & \multirow[b]{2}{*}{ Mean } & \multirow[b]{2}{*}{ SE } & \multirow[b]{2}{*}{$\begin{array}{l}\mathrm{p}- \\
\text { value } \\
\end{array}$} \\
\hline & Mean & $\mathrm{SE}$ & Mean & SE & & & \\
\hline \multicolumn{8}{|l|}{ Lipid profile } \\
\hline LDL-Ch, mg/dL & 3.80 & 2.05 & 1.09 & 2.27 & 3.07 & 3.07 & 0.317 \\
\hline HDL-Ch, $\mathrm{mg} / \mathrm{dL}^{\S}$ & -1.04 & 1.06 & -2.15 & 1.06 & 1.67 & 1.52 & 0.272 \\
\hline Total Ch, mg/dL & 5.17 & 2.74 & -0.07 & 2.82 & 6.77 & 3.73 & 0.069 \\
\hline Tryglicerides, $\mathrm{mg} / \mathrm{dL}^{\S}$ & 11.81 & 5.43 & 7.92 & 4.56 & 8.11 & 6.46 & 0.210 \\
\hline \multicolumn{8}{|l|}{$\begin{array}{l}\text { Kidney function } \\
\text { and serum } \\
\text { electrolytes } \\
\text { parameters }\end{array}$} \\
\hline Creatinine, $\mathrm{mg} / \mathrm{dL}^{\S}$ & 0.12 & 0.07 & 0.01 & 0.04 & 0.16 & 0.08 & 0.037 \\
\hline Calcium, mg/dL & -0.02 & 0.04 & 0.01 & 0.04 & 0.02 & 0.05 & 0.639 \\
\hline Sodium, $\mathrm{mmol} / \mathrm{L}^{\S}$ & 0.32 & 0.31 & 0.05 & 0.33 & 0.66 & 0.43 & 0.126 \\
\hline \multicolumn{8}{|l|}{$\begin{array}{l}\text { Inflammatory } \\
\text { markers }\end{array}$} \\
\hline CRP, g/L & -0.84 & 1.02 & 0.34 & 1.14 & -1.42 & 1.44 & 0.324 \\
\hline Glycaemia, g/L & -0.01 & 0.02 & 0.06 & 0.02 & -0.07 & 0.04 & 0.044 \\
\hline Vit $\mathrm{D}, \mathrm{nmol} / \mathrm{L}^{\S}$ & -10.3 & 2.99 & -12.8 & 3.37 & 0.02 & 4.12 & 0.997 \\
\hline
\end{tabular}

SE, Standard Error; CI, Confidence Interval; HDL-Ch, High Density Lipoprotein Cholesterol; LDL-Ch, Low Density Lipoprotein Cholesterol; CRP, C-reactive Protein; * p-values from mixed models, adjusted for before-intervention values; $\S$ significant period or sequence effect

\section{Discussion}

The current study produced two important findings: the first was that both the enriched and control Pecorino cheeses did not lead to an increase in LDL-Ch and the second one was that the fall in HDL-Ch was significantly lower in the group assuming the enriched Pecorino cheese with respect to that in the controls. According to some prospective studies, HDL cholesterol levels tend to fall with age in both men and women. [17,18] The most striking decreases, likely attributable to hormonal fluctuations, takes place in postmenopausal women [19]. Since the inverse correlation between HDL-Ch levels and coronary heart disease in the 1950s, the life cycle of HDL$\mathrm{Ch}$, its role in atherosclerosis and the therapeutic modification of HDL-Ch levels have been considered major research topics.

The Framingham study and many others have demonstrated that HDL-Ch is an independent cardiovascular risk factor and that an increase in HDL-Ch of only $10 \mathrm{mg} \cdot \mathrm{L}(-1)$ leads to a risk reduction of $2-3 \%$. [20] In light of these findings, new strategies and interventions are needed to further reduce the risk by increasing HDLCh or reducing its age-related decline. Being able to affect the decline in HDL-Ch with dietary interventions, such as the one we proposed in this study, could help to promote better cardiovascular health in older individuals but more studies are warranted to confirm these results.
However, there are only a few studies on the effects of CLA-enriched cheese on different lipid parameters in humans; in some cases no effects have emerged [9,21]; in others, LDL-Ch seems to be lowered by specific CLA isomers, and in still others the findings regarding HDL-Ch appear to be contradictory. [9]

Another important finding produced by the current study was that there was a lower reduction in Vit D concentration in the group assuming enriched Pecorino cheese. As is known, Vit D plays a critical role in bone health because it regulates the intestinal absorption of calcium. Study results concord with literature findings according to which a diet rich in PUFAs has a positive effect on bone metabolism and thus contributes to preventing and treating osteoporosis also thanks to the effects of PUFAs on vitamin D. [22]

Beyond bone health, Vit D has other roles in the body, including modulation of cell growth, neuromuscular and immune function, and reduction of inflammation. [23] Many genes encoding proteins that regulate cell proliferation, differentiation, and apoptosis are modulated in part by Vit D, and many cells have vitamin D receptors, and some convert $25(\mathrm{OH}) \mathrm{D}$ to $1,25(\mathrm{OH}) 2 \mathrm{D}$. Older adults are at increased risk of developing Vit D insufficiency because their skin is less capable of synthesizing it as efficiently, they tend to spend less time outdoors, and they may have inadequate intakes of the vitamin. [24] That means that a dietary intervention that is able to maintain vitamin D levels, preventing the fall seen in the control group, can have a relevant impact on the health of older individuals.

The increase in glycaemia that were found in both groups was significantly lower in the group eating enriched Pecorino cheese with respect to their counterparts, implying that it had a better effect on glucose metabolism with respect to the control one. Because hyperglycemia is often associated with obesity, hypertension, hyperlipidemia, and hyperuricemia, and of course leads to diabetes and cardiovascular diseases, major causes of disability and mortality, the positive impact of this nutritional intervention on glucose levels can have multiple health benefits at advanced ages.[25]

It is possible that consuming PUFAs instead of saturated fatty acids could improve insulin sensitivity; several epidemiologic studies have, in fact, described the positive effects of assuming foods rich in monounsaturated and or polyunsaturated fatty acids in preventing the development of diabetes. [26]

The current work does present some limitations: the primary ones are linked to the setting of the study's second phase which was carried out in a nursing home where residents tend to be fragile and often clinically unstable. In fact, many of the participants were unable to continue for health reasons or chose to drop out. This affected the number composing the population sample and underpowered the study to determine the change in the lipid parameters. In addition, it proved to be difficult to check and verify how much cheese was effectively being eaten by the participants and also the energy and macronutrient intake before and after intervention. Other limitations were linked to the short washout period (one months) and to the significant carry-over effect that was found in some blood parameters which is the reason that 
only the data gathered during the first phase of the study appeared reliable. On the positive side, the patients underwent exhaustive assessment and nearly all of the parameters examined were not based on self-reported data.

\section{Conclusions}

Our study found that assuming enriched Pecorino cheese has positive effects on HDL cholesterol, vitamin D, and on glucose levels. The elder participants of our study did not register an increase in lipid levels and thus in cardiovascular risk. We can thus hypothesize that a diet rich in PUFAs can have positive effects on cardiovascular disease, bone metabolism, and diabetes prevention. More studies on humans are warranted to evaluate in an exhaustive manner the role played by CLA enriched cheese on cardiovascular protection also by analyzing the association with other foods or diets.

\section{Acknowledgments}

The authors wish to thank Linda Inverso Moretti for reviewing the English version of this manuscript. The authors wish to thank also personnel of the OIC Foundation as well as the participants in the study.

\section{Financial Support}

The CLADIS Study was supported by Fondazione CARIPARO through the call "Progetto Eccellenza 20092010" (Grant Number 754, 13/10/2010).

Fondazione CARIPARO had no role in the design, analysis or writing of this article.

\section{Statement of Competing Interests}

The authors have no competing interests.

\section{List of Abbreviations}

\author{
Alpha-Linolenic acid (ALA) \\ Body Mass Index (BMI) \\ Conjugated Linoleic Acid (CLA) \\ C-reactive Protein (CRP) \\ Endocannabinoid (EC) \\ HDL-Cholesterol (HDL-Ch) \\ Intention-to-treat (ITT) \\ Linolenic acid (LNA) \\ Low Density Lipoproteins Cholesterol (LDL-Ch) \\ Polyunsaturated Fatty Acids (PUFA) \\ Saturated Fatty Acids (SFA) \\ Standard Deviations (SD)
}

\section{References}

[1] Rashidi Pour Fard, N., Karimi, M., Baghaei, M.H., Haghighatdoost, F., Rouhani, M.H., Esmaillzadeh, A. and Azadbakht, L, "Dairy consumption, cardiovascular risk factors and inflammation in elderly subjects" ARYA Atheroscler, 11(6), 323-331, November 2015.

[2] Qin, L.Q., Xu, J.Y., Han, S.F., Zhang, Z.L., Zhao, Y.Y. and Szeto, I.M, "Dairy consumption and risk of cardiovascular disease: an updated meta-analysis of prospective cohort studies", Asia Pac $J$ Clin Nutr, 24(1),90-100, 2015.

[3] Benatar, J.R., Sidhu, K. and Stewart, R.A, "Effects of high and low fat dairy food on cardio-metabolic risk factors: a metaanalysis of randomized studies", PLoS One, 8(10), e76480, October 2013

[4] Markey, O., Vasilopoulou, D., Givens, D.I. and Lovegrove, J.A, "Dairy and cardiovascular health: Friend or foe?", Nutr Bull 39(2), 161-171, June 2014

[5] Livingstone, K.M., Lovegrove, J.A. and Givens, D.I, “The impact of substituting SFA in dairy products with MUFA or PUFA on CVD risk: evidence from human intervention studies", Nutr Res Rev, 25(2),193-206, December 2012.

[6] Pintus, S., Murru, E., Carta, G., Cordeddu, L., Batetta, B., Accossu, S., Pistis, D., Uda, S., Elena Ghiani, M., Mele, M., Secchiari, P., Almerighi, G., Pintus, P. and Banni, S. "Sheep cheese naturally enriched in $\alpha$ linolenic, conjugated linoleic and vaccenic acids improves the lipid profile and reduces anandamide in the plasma of hypercholesterolaemic subjects", Br J Nutr 109(8),1453-1462, April 2013.

[7] Banni, S. and Di Marzo, V, "Effect of dietary fat on endocannabinoids and related mediators: consequences on energy homeostasis, inflammation and mood", Mol Nutr Food Res 54(1), 82-92, January 2010.

[8] Mele, M, "Designing milk fat to improve healthfulness and functional properties of dairy products: from feeding strategies to a genetic approach", Ital. J. Anim. Sci 8(Suppl. 2), 365-373, June 2009.

[9] Sofi, F., Buccioni, A., Cesari, F., Gori, A.M., Minieri, S., Mannini, L., Casini, A., Gensini, G.F., Abbate, R. and Antongiovanni, M, "Effects of a dairy product (pecorino cheese) naturally rich in cis9 , trans-11 conjugated linoleic acid on lipid, inflammatory and haemorheological variables: a dietary intervention study", Nutr Metab Cardiovasc Dis 20(2),117-124, February 2010.

[10] Bhattacharya, A., Banu, J., Rahman, M., Causey, J. and Fernandes, G, "Biological effects of conjugated linoleic acids in health and disease", J Nutr Biochem 17(12), 789-810, December 2006.

[11] Brouwer, I.A., Wanders, A.J. and Katan, M.B, "Effect of animal and industrial trans fatty acids on HDL and LDL cholesterol levels in humans--a quantitative review", PLoS One, 5(3):e9434, March 2010.

[12] Derakhshande-Rishehri, S.M., Mansourian, M., Kelishadi, R. and Heidari-Beni, M, "Association of foods enriched in conjugated linoleic acid (CLA) and CLA supplements with lipid profile in human studies: a systematic review and meta-analysis", Public Health Nutr, 18(11):2041-54, August 2015.

[13] Mele, M., Serra, A., Conte, G., Pollicardo, A., Del Viva, M. and Secchiari, P, "Whole extruded linseed in the diet of dairy ewes during early lactation: effect on the fatty acid composition of milk and cheese", Italian Journal of Animal Science 6(sup1), 560-562, 2007.

[14] Mele, M., Contarini, G., Cercaci, L., Serra, A., Buccioni, A., Povolo, M., Conte, G., Funaro, A., Banni, S., Lerckerc, G. and Secchiari, P, "Enrichment of Pecorino cheese with conjugated linoleic acid by feeding dairy ewes with extruded linseed: Effect on fatty acid and triglycerides composition and on oxidative stability", International Dairy Journal, 21(5), 365e372, May 2011.

[15] Standard 3433, International standards organization, ISO Cheese. Determination of fat content. Van Gulik method, Switzerland, 1975.

[16] AOAC, Official methods of analysis of the Association of Official Analytical Chemists, Association of Official Analytical Chemists, Washington DC, 1990, 2 vols. 15th ed.

[17] Wilson P.W.F., Anderson K.M., Harris T., Kannel, W.B. and Castelli, W.P, "Determinants of change in total cholesterol and HDLC with age: the Framingham study" J Gerontol, 49(6), M2527, November 1994.

[18] Ferrara, A., Barrett-Connor, E. and Shan, J, "Total, LDL, and HDL cholesterol decrease with age in older men and women The Rancho Bernardo Study 1984-1994", Circulation, 96(1), 37-43, July 1997.

[19] Marchi, R., Dell'Agnolo, C.M., Lopes, T.C.R., Gravena, A.A.F., Demitto, M.O., Brischiliari, S.C.R., Borghesan, D.H.P., Carvalho, 
M.D.B. and Pelloso, S.M, "Prevalence of metabolic syndrome in pre- and postmenopausal women", Arch Endocrinol Metab, 61(2):160-166, March-April 2017.

[20] Mahdy Ali, K., Wonnerth, A., Huber, K. and Wojta, J, "Cardiovascular disease risk reduction by raising HDL cholesterol - current therapies and future opportunities", $\mathrm{Br} J$ Pharmacol. 167(6), 1177-1194, November 2012.

[21] Tricon, S., Burdge, G.C., Jones, E.L., Russell, J.J., El-Khazen, S., Moretti, E., Hall, W.L., Gerry, A.B., Leake, D.S., Grimble, R.F., Williams, C.M., Calder, P.C. and Yaqoob, P, "Effects of dairy products naturally enriched with cis-9,trans-11 conjugated linoleic acid on the blood lipid profile in healthy middle-aged men", $A m \mathrm{~J}$ Clin Nutr, 83(4), 744-53, April 2006.

[22] El-Sayed, E. and Ibrahim, K, "Effect of the Types of Dietary Fats and Non-dietary Oils on Bone Metabolism", Crit Rev Food Sci Nutr, 4, 57(4), 653-658, March 2017.
[23] Institute of Medicine, Food and Nutrition Board,Dietary Reference Intakes for Calcium and Vitamin D, National Academy Press, Washington DC, 2010.

[24] Norman, A.W. and Henry, H.H. Vitamin D. In Bowman, B.A., Russell, R.M., eds. Present Knowledge in Nutrition, 9th ed, ILSI Press, Washington DC, 2006.

[25] Lai, SH., Tan, C.K. and Ng, K.C, "Epidemiology of Hyperglycemia in Elderly Persons", J Gerontol, 55(5), M257-9, May 2000.

[26] Ericson, U., Hellstrand, S., Brunkwall, L., Schulz, C.A., Sonestedt, E., Wallström, P., Gullberg, B., Wirfält, E. and Orho-Melander, M, "Food sources of fat may clarify the inconsistent role of dietary fat intake for incidence of type 2 diabetes", Am J Clin Nutr, 101(5), 1065-1080, May 20. 